http://dx.doi.org/10.1590/1678-4162-7971

Arq. Bras. Med. Vet. Zootec., v.68, n.2, p.497-505, 2016

\title{
Avaliação da correção da energia pelo balanço de nitrogênio em alimentos para frangos de corte
}

\author{
[Evaluation of the energy correction for nitrogen balance \\ in feed for broiler chickens] \\ R.C. Andrade ${ }^{1}$, L.J.C. Lara ${ }^{1}$, M.A.Pompeu ${ }^{1}$, P.C. Cardeal ${ }^{1}$, \\ D.J.A. Miranda ${ }^{2}$, N.C. Baião \\ ${ }^{1}$ Escola de Veterinária - EV-UFMG - Belo Horizonte, MG \\ ${ }^{2}$ Faculdade de Agronomia - UFRGS, Porto Alegre, RS
}

\begin{abstract}
RESUMO
Com o objetivo de determinar valores de energia metabolizável aparente e de energia metabolizável aparente corrigida pelo balanço de nitrogênio de alimentos para frangos de corte, bem como avaliar os efeitos da correção da energia sobre seu desempenho, foram conduzidos dois experimentos: I) determinação da energia do milho, do farelo de soja, da farinha de carne e ossos, da farinha de vísceras e da farinha de penas, pelo método de coleta total de excretas, utilizando-se 450 pintos de corte com um dia de idade, distribuídos em delineamento inteiramente ao acaso, sendo seis tratamentos e cinco repetições; II) desempenho de 960 frangos de corte, distribuídos ao acaso, em cinco tratamentos e seis repetições. As aves que receberam os tratamentos A (matriz energética de acordo com Rostagno et al. (2011)) e E (energia sem correção com ajuste pela idade) apresentaram melhor desempenho, e as aves do tratamento E tiveram melhor conversão alimentar. Portanto, formulações com energia sem correção pelo balanço de nitrogênio e ajustadas pela idade são viáveis tanto sob o ponto de vista zootécnico, quanto econômico.
\end{abstract}

Palavras-chave: aves, custo, desempenho, formulação, nutrição

\begin{abstract}
In order to determine apparent metabolizable energy and apparent metabolizable energy corrected by nitrogen balance of feed ingredients and to evaluate the effects of this correction on performance of broiler chickens, two experiments were conducted: I) energy determination of corn, soybean meal, meat and bone meal, poultry by-products meal and feather meal by total excreta collection method, using 450 chicks randomly distributed in 30 cages, with 6 treatments and 5 replications; II) performance of 960 broilers, distributed in a completely randomized design, with 5 treatments and 6 replications. Birds that received treatments $A$ (energy matrix from literature) and $E$ (energy without correction adjusted by age) showed better performance with the best feed cost, and treatment $E$ had smaller feed conversion ratio. Therefore, the use of formulations based on metabolizable energy adjusted for age and without correction by nitrogen balance is feasible, both from a zootechnical and economic point of view.
\end{abstract}

Keywords:costs, formulation, performance, nutrition, poultry

\section{INTRODUÇÃO}

Além de interferir diretamente no desempenho dos frangos de corte, a energia é um dos fatores nutricionais que mais onera o custo das rações. A energia metabolizável aparente corrigida pelo balanço de nitrogênio difere da energia

Recebido em 9 de agosto de 2014

Aceito em 3 de dezembro de 2015

E-mail: raq2000@hotmail.com metabolizável aparente pela correção associada ao balanço de nitrogênio. Essa correção baseia-se no fato de que, em aves em crescimento, a proteína retida no organismo não contribui para a energia das fezes e da urina. O objetivo dessa correção é padronizar e reduzir a variação nos valores de energia metabolizável dos alimentos medidos em diferentes condições. 
Lopez e Leeson (2008), ao avaliarem a correção da energia metabolizável aparente pelo balanço de nitrogênio, constataram que essa correção impõe uma penalidade de 3 a 5\% na energia do milho e de 7 a $12 \%$ na energia do farelo de soja, demonstrando que sua utilização pode incrementar os custos de ração sem benefícios ao desempenho dos frangos de corte.

Geralmente se atribui que a energia da dieta vem de ingredientes particularmente ricos em energia, como milho, sorgo, trigo ou óleos e gorduras. Entretanto, é importante lembrar que todos os ingredientes fornecem energia e que, em dietas de alta proteína, produtos como o farelo de soja podem contribuir substancialmente com a energia total da dieta (Leeson e Summers, 2001). Desse modo, a utilização de valores de energia metabolizável aparente corrigida para o balanço do nitrogênio de alimentos para frangos de corte em crescimento pode penalizar a energia contida principalmente em alimentos proteicos, subestimando a matriz nutricional e aumentando os custos de formulação das rações.

Considerando que um maior conhecimento das matrizes nutricionais usadas na formulação de rações é uma importante ferramenta de melhoria de resultados, este trabalho teve como objetivos determinar os valores de energia metabolizável aparente corrigida ou não pelo balanço de nitrogênio de diferentes alimentos para frangos de corte de diferentes idades e avaliar a correção da energia metabolizável pelo balanço de nitrogênio, os impactos econômicos dessa correção sobre a matriz nutricional de alimentos para aves e seu efeito sobre o desempenho.

\section{MATERIAL E MÉTODOS}

Para determinar valores de energia metabolizável aparente e de energia metabolizável aparente corrigida pelo balanço de nitrogênio de milho, farelo de soja, farinha de carne e ossos, farinha de vísceras de aves e farinha de penas, um ensaio foi conduzido no Laboratório de Metabolismo Animal (LAMA), UFMG (Protocolo CETEA 222/2010). A determinação da energia metabolizável dos alimentos foi realizada pelo método de coleta total de excretas nos períodos de sete a 10 (fase inicial) e de 26 a 29 dias de idade (fase de crescimento), num delineamento inteiramente ao acaso.
Para a fase inicial, 450 pintos de corte machos da linhagem Cobb 500 Slow com um dia de idade foram alojados em 30 gaiolas metálicas de $1,0 \mathrm{~m}^{2}$, sendo seis tratamentos e cinco repetições de 15 aves cada. Para a fase de crescimento, foram alojados 300 pintos de corte machos da linhagem Cobb 500 Slow de um dia de idade nas instalações experimentais da Fazenda Experimental "Professor Hélio Barbosa" da Escola de Veterinária da UFMG, em Igarapé$\mathrm{MG}$, onde foram criados até 21 dias de idade, em cama de cepilho de madeira sobre piso, com água e ração à vontade de acordo com as exigências nutricionais recomendadas por Rostagno et al. (2011). Aos 22 dias de idade, as aves foram transferidas para o LAMA e distribuídas em 30 gaiolas metálicas de $1,0 \mathrm{~m}^{2}$, sendo seis tratamentos e cinco repetições de 10 aves cada. As gaiolas possuíam bandejas próprias para coleta de excretas e eram equipadas com comedouros e bebedouros, permitindo consumo de ração e água à vontade. $\mathrm{O}$ período de adaptação às dietas teste e às gaiolas foi de três dias, com posteriores quatro dias de coleta total de excretas, sendo realizadas duas coletas por dia.

Foram utilizadas 12 rações experimentais, sendo seis para a fase inicial e seis para a fase de crescimento, preparadas a partir de uma dieta básica composta de milho, farelo de soja, óleo de soja, macro e microminerais, vitaminas, aminoácidos e aditivos. Para as rações basais, foram utilizados os níveis nutricionais propostos por Rostagno et al. (2011). A substituição dos alimentos nas rações basais foi de $40 \%$ para o milho e de $25 \%$ para os demais ingredientes (farelo de soja, farinha de carne e ossos, farinha de vísceras e farinha de penas). Cada alimento estudado foi considerado um tratamento, além do tratamento com a ração basal, para a composição dos cálculos da energia.

Para a coleta das excretas, foram utilizadas bandejas cobertas com plástico colocadas sob as gaiolas. Para estabelecer o início e o final da coleta, foi realizado jejum alimentar de quatro e seis horas para as fases inicial e de crescimento, respectivamente. Após coletadas, as excretas foram acondicionadas em sacos plásticos, devidamente identificadas, pesadas e mantidas em câmara frigorífica a $-8^{\circ} \mathrm{C}$. As excretas foram descongeladas à temperatura ambiente e homogeneizadas para a retirada de duas amostras 
por unidade experimental. As amostras foram secas em estufa de ventilação forçada a $55^{\circ} \mathrm{C}$ por 72 horas, moídas e encaminhadas para análises de matéria seca, nitrogênio e energia bruta. Com base nos dados de consumo de ração, produção de excretas, análises de matéria seca, nitrogênio e energia bruta das rações e das excretas, foram determinadas a energia metabolizável aparente e a energia metabolizável aparente corrigida para o balanço de nitrogênio (Matterson et al.,1965).

Para avaliar os efeitos da correção da energia metabolizável pelo balanço de nitrogênio sobre desempenho zootécnico e econômico de frangos de corte, um experimento foi realizado na Fazenda Experimental "Professor Hélio Barbosa". Foram utilizados 960 pintos de corte, machos da linhagem Cobb 500 Slow, de um dia de idade, distribuídos em delineamento inteiramente ao acaso, em galpão experimental dividido em boxes de $2,50 \mathrm{~m}^{2}$ cada, forrados com cepilho de madeira, onde foram criados até 41 dias de idade, sendo cinco tratamentos e seis repetições. Água e ração foram fornecidas ad libitum.

Foram utilizados quatro tipos de rações, de acordo com a fase de criação, sendo pré-inicial de um a sete dias, inicial de oito a 21 dias, crescimento de 22 a 35 dias e final de 36 a 41 dias de idade (Lara et al., 2008). Para a formulação das rações, os níveis nutricionais dos ingredientes foram considerados conforme os valores propostos por Rostagno et al. (2011), exceto pelos níveis de energia. Estes foram baseados, além dos níveis propostos por Rostagno et al. (2011), nos valores obtidos no experimento I, determinando os planos nutricionais definidos como tratamentos.

Os tratamentos foram definidos como: $\mathrm{A}=$ energia metabolizável aparente corrigida pelo balanço de nitrogênio de acordo com Rostagno et al. (2011) para todas as fases de criação; B = energia metabolizável aparente corrigida pelo balanço de nitrogênio, encontrada no experimento I no período de coleta entre 26 e 29 dias de idade para todas as fases de criação; $\mathrm{C}=$ energia metabolizável aparente encontrada no experimento I no período de coleta entre 26 e 29 dias de idade para todas as fases de criação; D = energia metabolizável aparente corrigida pelo balanço de nitrogênio encontrada no experimento I no período de coleta entre sete e 10 dias para as rações pré-inicial e inicial e no período de coleta entre 26 e 29 dias de idade para as rações crescimento e final; $\mathrm{E}=$ energia metabolizável aparente encontrada no experimento I no período de coleta entre sete e 10 dias para as rações préinicial e inicial e no período de coleta entre 26 e 29 dias de idade para as rações crescimento e final.

Foram realizadas avaliações de desempenho (peso corporal, ganho de peso, consumo de ração, conversão alimentar, viabilidade), aos sete, 21 e 41 dias de idade, e de custo da ração por $\mathrm{kg}$ de frango produzido, multiplicando-se o custo da ração consumida pela conversão alimentar, além do índice de eficiência produtiva, usado largamente pela indústria avícola, multiplicando-se o ganho de peso diário pela viabilidade e dividindo-se o resultado pela conversão alimentar. Para os custos das rações, foi considerada planilha de custo semanal da empresa Frangoeste Avicultura Ltda. (Tietê-SP), de 02 de fevereiro de 2012, exceto pelos suplementos minerais e vitamínicos cujos custos foram considerados preços de venda da empresa Vaccinar Indústria e Comercio Ltda.

Todas as variáveis foram submetidas à análise de variância e comparadas pelo teste de Tukey, exceto a variável "viabilidade", que violou os princípios de normalidade, sendo analisada pelo teste de Kruskal-Wallis, elencando-se a probabilidade de 5\%. As análises estatísticas foram realizadas por meio do programa SAEG (SAEG, 2007).

\section{RESULTADOS E DISCUSSÃO}

Os resultados de energia metabolizável aparente (com ou sem correção pelo balanço de nitrogênio) de milho, farelo de soja, farinha de carne e ossos, farinha de vísceras e farinha de penas determinados estão apresentados na Tab. 1 , bem como a diferença percentual entre esses valores.

Houve efeito da idade e da correção pelo balanço de nitrogênio $(\mathrm{P}<0,01)$ entre os valores de energia do milho, do farelo de soja e da farinha de penas. Nesses ingredientes, os valores de energia metabolizável aparente foram maiores do que os valores corrigidos pelo balanço de nitrogênio, e os valores determinados com aves mais velhas (26 a 29 dias) foram maiores do que 
com aves mais jovens (sete a 10 dias). Aves jovens têm crescimento acelerado e, nesse período, ocorre intensa deposição muscular, ou seja, maior retenção de nitrogênio. As diferenças entre energia metabolizável aparente e energia metabolizável aparente corrigida pelo balanço de nitrogênio são mais significativas quando os ingredientes são particularmente proteicos, como o farelo de soja e o da farinha de penas, o que também foi evidenciado por Lopez e Leeson (2008).

Tabela 1. Energia metabolizável aparente (EMA) e energia metabolizável aparente corrigida para o balanço de nitrogênio (EMAn) de alimentos para frangos de corte em diferentes idades, com base na matéria seca, e a diferença percentual entre EMA e EMAn

\begin{tabular}{lcccc}
\hline \multirow{2}{*}{ Milho } & Idade (dias) & EMA $(\mathrm{kcal} / \mathrm{kg})$ & EMAn $(\mathrm{kcal} / \mathrm{kg})$ & Diferença $(\%)$ \\
\hline \multirow{2}{*}{ Farelo de soja } & 07 a 10 & $3.507 \mathrm{Ab}$ & $3.382 \mathrm{Bb}$ & 3,56 \\
& 26 a 29 & $3.769 \mathrm{Aa}$ & $3.654 \mathrm{Ba}$ & 3,06 \\
\hline \multirow{2}{*}{ Farinha de carne e ossos } & 07 a 10 & $2.092 \mathrm{Ab}$ & $1.804 \mathrm{Bb}$ & 13,80 \\
& 26 a 29 & $2.546 \mathrm{Aa}$ & $2.328 \mathrm{Ba}$ & 8,56 \\
\hline \multirow{2}{*}{ Farinha de vísceras } & 07 a 10 & $2.378 \mathrm{~A}$ & $2.093 \mathrm{~B}$ & 11,94 \\
& 26 a 29 & $2.335 \mathrm{~A}$ & $2.111 \mathrm{~B}$ & 9,60 \\
\hline \multirow{2}{*}{ Farinha de penas } & 07 a 10 & $4.293 \mathrm{~A}$ & $3.872 \mathrm{~B}$ & 8,92 \\
& 26 a 29 & $4.326 \mathrm{~A}$ & $3.877 \mathrm{~B}$ & 10,38 \\
\hline
\end{tabular}

Médias seguidas de letras maiúsculas na linha e minúsculas na coluna diferem significativamente entre si, pelo teste Tukey $(\mathrm{P}<0,01)$

Para farinha de carne e ossos e farinha de vísceras, houve efeito da correção pelo balanço de nitrogênio nos valores de energia determinados, mas não houve diferença do valor de energia entre as diferentes idades. A energia de farinha de carne e ossos e de farinha de vísceras é resultado, principalmente, da quantidade de gordura presente nesses alimentos, que é bastante significativa. A digestibilidade da gordura em pintos ao nascer é alta, sofre redução na segunda semana de vida em razão da adaptação enzimática e aumenta novamente, atingindo seu ápice a partir dos 17 dias de idade (Freitas et al., 1999).

Os valores de energia metabolizável aparente encontrados foram superiores aos de energia metabolizável aparente corrigida pelo balanço de nitrogênio em média de $3,3 \%$ para o milho, $11,2 \%$ para o farelo de soja, $10,8 \%$ para a farinha de carne e ossos, $10,1 \%$ para a farinha de vísceras e $11,9 \%$ para a farinha de penas. Nery et al. (2007) trabalharam com aves de 21 a 31 dias de idade e determinaram valores de energia metabolizável aparente, em média, 2,72\% superiores aos de energia metabolizável aparente corrigida pelo balanço de nitrogênio. Já Nunes et al. (2008) encontraram valores, em média, 4,47\% superiores para frangos com 28 a 32 dias de idade.
Os valores de energia metabolizável aparente corrigida pelo balanço de nitrogênio encontrados para todos os ingredientes estudados são inferiores aos propostos por Rostagno et al. (2011), principalmente quando comparados àqueles determinados em aves de sete a 10 dias de idade. Entretanto, os valores de farinha de carne e ossos e de farinha de vísceras estão de acordo com a variação proposta pelos mesmos pesquisadores em razão das diferentes composições desses alimentos. A inferioridade nos valores provavelmente ocorre devido ao fato de as idades de determinação serem distintas entre os trabalhos, uma vez que Rostagno et al. (2011) determinaram os valores de energia metabolizável aparente corrigida pelo balanço de nitrogênio com base em diversos trabalhos, com determinações em diferentes idades.

Nota-se claramente que, quando há maior retenção de nitrogênio, ou seja, maior deposição muscular (aves mais jovens e com crescimento mais acelerado), há maior penalização da energia metabolizável em razão da correção pelo balanço de nitrogênio. Entretanto, teores mais elevados de proteína no ingrediente não promoveram maior penalização ou maior retenção relativa de nitrogênio nas aves.

Esses resultados estão de acordo com Lopez e Leeson (2008), que constataram que a correção 
da energia metabolizável aparente pelo balanço de nitrogênio impôs uma penalidade de 3 a $5 \%$ na energia do milho e de 7 a $12 \%$ na energia do farelo de soja para frangos de corte. Nunes et al. (2008) demonstraram penalização da energia metabolizável em 2,4 e 2,5\%, em razão da correção pelo balanço de nitrogênio em aves de 28 a 32 dias de idade. Já Carvalho (2010), ao trabalhar com frangos de corte de diferentes idades, observou penalizações entre 1,3 e 1,8\% para o milho e 4,6 e $8,0 \%$ para o farelo de soja, respectivamente.

Paula et al. (2002) apresentaram penalização de $10,7 \%$ para farinha de carne e ossos, enquanto Tucci et al. (2003) encontraram diferenças de $0,05 \%, \quad 1,35 \%$ e $0,09 \%$ para diferentes fornecedores de farinha de carne e ossos. Para pintos de zero a sete dias, os valores determinados por Soares et al. (2005) foram, em média, $12 \%$ de penalização para diferentes farinhas de carne e ossos e 12,7\% para farinha de vísceras.

Ao trabalharem com frangos de diferentes idades, Nascimento et al. (2005) encontraram penalização na determinação da energia de 9,2\% no período de 16 a 23 dias e de $14,7 \%$ no período de 30 a 38 dias para farinha de vísceras. Para farinha de penas, os valores encontrados foram de $11,8 \%$ no período de 16 a 23 dias e de $10,4 \%$ no período de 30 a 38 dias de idade. Mello et al. (2009) avaliaram farinha de vísceras e farinha de penas e encontraram penalizações médias de $0,79 \%$ e 1,2\% nas idades de 10 a 17 dias e de 26 a 33 dias, respectivamente, para farinha de vísceras e de $0,47 \%$ e $1,05 \%$ para farinha de penas.

Com os resultados apresentados, observa-se que aves mais jovens aproveitam menos energia dos alimentos do que aves mais velhas, principalmente em se tratando de ingredientes vegetais. A penalização da determinação da energia metabolizável em razão da correção pelo balanço de nitrogênio também é mais representativa em aves mais jovens e pode ultrapassar $10 \%$ em ingredientes proteicos, o que pode interferir negativamente nos custos de produção.

Os resultados de desempenho obtidos estão apresentados na Tab.2. Não houve diferença significativa $(\mathrm{P}<0,05)$ para os pesos iniciais dos pintos nem para a viabilidade das aves em todos os períodos de criação avaliados.

Tabela 2. Peso vivo (PV), ganho de peso diário (GPD), consumo de ração (CR), conversão alimentar (CA) e viabilidade (VIAB) de frangos de corte no período de um a sete dias, um a 21e um a 41 dias de idade

\begin{tabular}{|c|c|c|c|c|c|c|}
\hline & $\begin{array}{c}\text { Planos } \\
\text { nutricionais }\end{array}$ & $\begin{array}{l}\text { PV } \\
\text { (g) }\end{array}$ & $\begin{array}{l}\text { GPD } \\
\text { (g/dia) }\end{array}$ & $\begin{array}{l}\text { CR } \\
(\mathrm{g})\end{array}$ & $\begin{array}{l}\text { CA } \\
(\mathrm{g}: \mathrm{g})\end{array}$ & $\begin{array}{l}\text { VIAB }^{1} \\
(\%)\end{array}$ \\
\hline \multirow{6}{*}{ 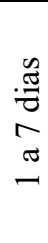 } & $\mathrm{A}$ & $192,67 a$ & $21,74 a$ & $159,84 a$ & $1,0502 \mathrm{c}$ & 100,00 \\
\hline & B & $193,19 a$ & $21,80 \mathrm{a}$ & $153,77 b c$ & $1,0083 \mathrm{ab}$ & 100,00 \\
\hline & $\mathrm{C}$ & $191,06 \mathrm{ab}$ & $21,51 \mathrm{ab}$ & $156,34 \mathrm{ab}$ & $1,0384 b c$ & 99,99 \\
\hline & $\mathrm{D}$ & $185,07 \mathrm{~b}$ & $20,68 b$ & $140,63 d$ & $0,9721 \mathrm{a}$ & 99,99 \\
\hline & $\mathrm{E}$ & $191,29 \mathrm{ab}$ & $21,56 \mathrm{ab}$ & $149,11 \mathrm{c}$ & $0,9883 \mathrm{a}$ & 99,99 \\
\hline & $\mathrm{CV}(\%)$ & 1,97 & 2,52 & 2,08 & 2,39 & - \\
\hline \multirow{6}{*}{ 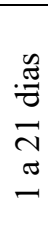 } & $\mathrm{A}$ & $1024,83 \mathrm{ab}$ & $46,87 \mathrm{ab}$ & $1279,29 a$ & $1,2996 \mathrm{~d}$ & 99,98 \\
\hline & B & $1049,01 \mathrm{a}$ & $48,02 \mathrm{a}$ & $1238,61 b c$ & $1,2283 b$ & 99,99 \\
\hline & $\mathrm{C}$ & $1039,40 \mathrm{a}$ & $47,57 \mathrm{a}$ & $1277,44 \mathrm{ab}$ & $1,2787 \mathrm{c}$ & 99,99 \\
\hline & $\mathrm{D}$ & $1004,12 b$ & $45,89 b$ & $1157,17 d$ & $1,2008 \mathrm{a}$ & 99,99 \\
\hline & E & $1030,31 \mathrm{ab}$ & $47,14 \mathrm{ab}$ & $1211,29 \mathrm{c}$ & $1,2237 b$ & 99,97 \\
\hline & CV $(\%)$ & 1,80 & 1,88 & 1,92 & 0,92 & - \\
\hline \multirow{6}{*}{ 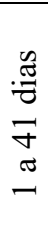 } & $\mathrm{A}$ & 3055,17 & 73,53 & $4834,21 \mathrm{a}$ & $1,6037 \mathrm{c}$ & 99,94 \\
\hline & B & 3073,81 & 73,98 & $4644,64 b c$ & $1,5315 \mathrm{ab}$ & 99,95 \\
\hline & $\mathrm{C}$ & 3012,84 & 72,50 & $4759,33 \mathrm{ab}$ & $1,6014 c$ & 99,96 \\
\hline & $\mathrm{D}$ & 3028,85 & 72,89 & $4512,60 \mathrm{c}$ & $1,5101 \mathrm{a}$ & 99,95 \\
\hline & E & 3028,20 & 72,87 & $4639,41 b c$ & $1,5531 \mathrm{~b}$ & 99,92 \\
\hline & CV (\%) & 2,39 & 2,42 & 1,91 & 0,98 & - \\
\hline
\end{tabular}

Médias seguidas por letras distintas diferem significativamente pelo teste de Tukey $(\mathrm{P}<0,01)$; ${ }^{1}$ não significativo pelo teste de Kruskal-Wallis. 
Houve efeito dos tratamentos sobre o peso aos sete dias e ganho de peso diário de zero a sete dias de idade $(\mathrm{P}<0,05)$. As aves que receberam os planos nutricionais A e B tiveram os maiores pesos aos sete dias de idade e maiores ganhos de peso diário em relação às aves que receberam o plano nutricional $\mathrm{D}$, o que provavelmente ocorreu devido ao maior consumo de alimento. As aves que receberam os planos nutricionais $\mathrm{C} \mathrm{e}$ $\mathrm{E}$ apresentaram valores intermediários aos demais planos nutricionais.

O consumo de ração de zero a sete dias de idade diferiu entre todos os planos nutricionais, exceto pelos planos nutricionais $\mathrm{A}$ e $\mathrm{C}$ e $\mathrm{B}$ e $\mathrm{C}$, que tiveram resultados semelhantes $(\mathrm{P}<0,05)$. As aves que receberam o plano nutricional $A$ apresentaram o maior consumo de ração em relação às aves que receberam os planos nutricionais $\mathrm{B}, \mathrm{D}$ e $\mathrm{E}$. As aves que receberam o plano nutricional $\mathrm{D}$ tiveram menor consumo de ração. A diferença entre os consumos de ração pode ser explicada pela quantidade de óleo incluída nas rações, que está diretamente relacionada ao nível de energia absoluta nas rações, uma vez que há diferença entre as matrizes energéticas dos ingredientes em cada plano nutricional e o consumo de alimento pode ser regulado pela ingestão de energia nessa fase da vida do frango.

Houve diferença dos planos nutricionais em relação à conversão alimentar de zero a sete dias de idade $(\mathrm{P}<0,05)$. As aves que receberam os planos nutricionais D e E apresentaram melhor conversão alimentar que as aves que receberam os planos nutricionais A e C. Isso porque as aves que tiveram as melhores conversões foram as que tiveram seu consumo de alimento mais limitado em razão do nível energético das dietas ou das maiores inclusões de óleo nessas rações.Como a fase pré-inicial (zero a sete dias) tem pouca representatividade em relação ao custo alimentar das aves, é mais interessante que as aves apresentem maior peso, independentemente do consumo de ração, pois existe alta correlação entre o peso aos sete dias e o peso final das aves (Rocha et al., 2008).

Houve efeito dos planos nutricionais sobre o peso médio das aves aos 21 dias e sobre o ganho de peso diário de zero a 21 dias de idade $(\mathrm{P}<0,05)$. As aves que receberam os planos nutricionais $\mathrm{B}$ e $\mathrm{C}$ apresentaram maior peso e maior ganho de peso diário que as aves que receberam o plano nutricional $\mathrm{D}$. As aves que receberam os planos nutricionais $\mathrm{A}$ e $\mathrm{E}$ tiveram pesos intermediários. A semelhança entre o peso aos 21 dias e o ganho de peso diário no período de zero a 21 dias demonstra a interferência do baixo peso aos sete dias limitado pelo consumo de ração das aves que receberam o plano nutricional D.

Houve efeito dos tratamentos sobre o consumo de ração e a conversão alimentar das aves de zero a 21 dias de idade $(\mathrm{P}<0,05)$. Nesse período, o consumo de ração diferiu entre todos os planos nutricionais, exceto nos planos nutricionais A e $\mathrm{C}$ e $\mathrm{B}$ e $\mathrm{C}$, que tiveram resultados semelhantes. $\mathrm{O}$ maior consumo de ração foi apresentado pelas aves que receberam o plano nutricional $\mathrm{A}$, enquanto os menores valores foram obtidos com as aves que receberam os planos $D$ e E, respectivamente. As aves que receberam os planos nutricionais $\mathrm{B}$ e $\mathrm{C}$ tiveram valores intermediários de consumo de ração. Mais uma vez, houve interferência do valor energético do alimento sobre o consumo voluntário de ração.

A melhor conversão alimentar de zero a 21 dias foi apresentada pelas aves que receberam o plano nutricional $\mathrm{D}$, seguidas pelas que receberam os planos nutricionais $\mathrm{B} e \mathrm{E}, \mathrm{C}$ e $\mathrm{A}$, respectivamente; os planos $\mathrm{B}$ e $\mathrm{E}$ tiveram resultados semelhantes. A melhor conversão alimentar das aves do tratamento $\mathrm{D}$ foi influenciada pelo baixo consumo devido à maior inclusão de óleo na ração, e, assim, o melhor desempenho da fase inicial ocorreu entre as aves que receberam os planos alimentares $\mathrm{B}$ e E. Ou seja, foram mais apropriadas a atender às exigências nutricionais das aves até os 21 dias de idade formulações que utilizaram energia metabolizável aparente corrigida pelo balanço de nitrogênio determinada com aves de 26 a 29 dias de idade, bem como energia metabolizável aparente, sem correção para o balanço de nitrogênio, com a energia ajustada para cada fase de acordo com a determinação de sete a 10 dias para as fases iniciais e de 26 a 29 dias para as fases de crescimento e final, respectivamente.

As aves que receberam os tratamentos $\mathrm{A}$ e $\mathrm{C}$ apresentaram maior consumo de alimento, quando comparadas às aves que receberam o tratamento $\mathrm{D}(\mathrm{P}<0,05)$. Houve semelhança entre o consumo de ração das aves que receberam os planos nutricionais $\mathrm{A}, \mathrm{B}$ e $\mathrm{C}, \mathrm{B}$ e $\mathrm{E}$ e $\mathrm{D}$ e $\mathrm{E}$ $(\mathrm{P}>0,05)$. 
Não houve efeito dos planos nutricionais sobre o peso aos 41 dias nem sobre o ganho de peso diário das aves de zero a 41 dias de idade $(\mathrm{P}>0,05)$, porém houve efeito significativo sobre o consumo de ração e a conversão alimentar de zero a 41 dias $(\mathrm{P}<0,05)$. O maior consumo de alimento foi observado entre as aves que receberam o tratamento $\mathrm{A}$, quando comparadas às aves que receberam o tratamento $\mathrm{B}, \mathrm{D}$ e $\mathrm{E}$. As aves que receberam o plano nutricional $\mathrm{C}$ tiveram consumos intermediários.

As aves que receberam o tratamento D obtiveram a melhor conversão alimentar em detrimento daquelas que receberam os tratamentos $\mathrm{A}, \mathrm{C}$ e $\mathrm{E}$. As aves que receberam o tratamento $\mathrm{B}$ obtiveram resultados intermediários.

Com base nos resultados finais obtidos, é possível inferir que a formulação ajustada para a energia metabolizável aparente corrigida pelo balanço de nitrogênio determinada com aves de 26 a 29 dias de idade foi mais adequada para atender às exigências energéticas das aves (planos nutricionais $\mathrm{B}$ e $\mathrm{D}$ ), seguidas da formulação que utilizou a energia metabolizável aparente, sem correção para o balanço de nitrogênio, com a energia ajustada para cada fase de acordo com a determinação de sete a 10 dias para as fases iniciais e de 26 a 29 dias para as fases de crescimento e final (plano nutricional E).

Esses resultados se mostram interessantes no sentido de que as exigências energéticas adotadas para a formulação estão superestimadas em relação às energias sugeridas por Rostagno et al. (2011) para a matriz nutricional dos ingredientes. Independentemente da exigência energética adotada, apesar do baixo desempenho na fase inicial em razão da restrição do consumo dos tratamentos D e E, houve efeito benéfico do maior uso de óleo na formulação, conforme descrito por Junqueira et al. (2005).

Freitas et al. (2006), ao trabalharem com formulações com energia metabolizável corrigida ou não pelo balanço de nitrogênio, observaram que, para pintos de um a 21 dias, a formulação baseada na energia metabolizável aparente corrigida pelo balanço de nitrogênio foi mais adequada para consumo de ração, ganho de peso e conversão alimentar das aves. Contudo, Lopez e Leeson (2008), ao avaliarem a correção da energia metabolizável aparente pelo balanço de nitrogênio para frangos de corte, constataram que essa correção impôs uma penalidade de 3 a $5 \%$ na energia do milho e de 7 a $12 \%$ na energia do farelo de soja, demonstrando que sua utilização pode incrementar os custos de ração sem benefícios ao desempenho das aves.

A apuração dos custos de ração por kg de frango, bem como os índices de eficiência produtiva obtidos, de acordo com os diferentes planos nutricionais, está apresentada na Tab. 3. Houve efeito dos planos alimentares sobre o custo da ração por kg de frango e sobre o IEP $(\mathrm{P}<0,05)$. As aves que receberam o plano nutricional $A$ tiveram melhor custo alimentar, quando comparadas às aves que receberam os planos nutricionais $\mathrm{B}$ e $\mathrm{D}$, uma vez que, com a matriz nutricional mais subestimada, as correções para atingir o nível energético com maior inclusão de óleo são bastante onerosas. As aves que receberam os demais planos nutricionais tiveram custos alimentares intermediários, com semelhança entre os planos nutricionais, conforme segue: A, C e E; B, C e E; e B e D.

Tabela 3. Custo médio da ração, custo alimentar ${ }^{2}$ e índice de eficiência produtiva de frangos de corte machos aos 41 dias de idade

\begin{tabular}{|c|c|c|c|}
\hline Planos nutricionais & $\begin{array}{l}\text { Custo médio de ração } \\
\text { (R\$/ton) }\end{array}$ & $\begin{array}{c}\text { Custo alimentar }^{1} \\
\text { (R\$/kg frango) }\end{array}$ & $\begin{array}{l}\text { Índice de eficiência } \\
\text { produtiva (pontos) }\end{array}$ \\
\hline $\mathrm{A}$ & 654,20 & $1,0484 a$ & $458,27 \mathrm{ab}$ \\
\hline B & 702,90 & $1,0756 b c$ & $483,01 \mathrm{a}$ \\
\hline $\mathrm{C}$ & 665,00 & $1,0643 \mathrm{ab}$ & $452,63 b$ \\
\hline $\mathrm{D}$ & 725,00 & $1,0908 \mathrm{c}$ & $482,53 a$ \\
\hline $\mathrm{E}$ & 685,10 & $1,0608 \mathrm{ab}$ & $469,00 \mathrm{ab}$ \\
\hline $\mathrm{CV}(\%)$ & - & 0,99 & 3,15 \\
\hline $\mathrm{P}$ & - & 0,0000 & 0,0044 \\
\hline
\end{tabular}

Médias seguidas por letras distintas diferem significativamente pelo teste de Tukey $(\mathrm{P}<0,01)$; custo alimentar $=$ conversão alimentar x custo médio da ração, baseado nos custos de matéria-prima de integração em SP, em fevereiro de 2012. 
Aves que receberam os planos nutricionais B e D tiveram IEP superior às aves que receberam $\mathrm{o}$ plano nutricional $\mathrm{C}$, enquanto as aves que receberam os planos nutricionais $\mathrm{A}$ e $\mathrm{E}$ tiveram resultados intermediários. Houve semelhança entre as aves que receberam os planos nutricionais $\mathrm{A}, \mathrm{B}, \mathrm{D}$ e $\mathrm{E}$ e entre as aves que receberam os planos nutricionais $\mathrm{A}, \mathrm{C}$ e $\mathrm{E}$.

Entre os melhores custos alimentares, o melhor desempenho foi obtido pelas aves que receberam o plano nutricional E. Nesse cenário, é possível inferir que o ajuste da energia de acordo com a idade e o não uso da correção pelo balanço de nitrogênio, já que frangos de corte são criados em pleno crescimento (retenção de nitrogênio), podem ser utilizados como parâmetro para a formulação de rações comercialmente.

\section{CONCLUSÕES}

Os valores de energia atribuídos aos ingredientes utilizados na formulação de rações para frangos de corte apresentaram variações principalmente em razão da idade das aves utilizadas na determinação da energia. A correção pelo balanço de nitrogênio penalizou a determinação de energia metabolizável com impacto econômico na formulação de rações. Portanto, a utilização de formulações com a energia metabolizável ajustada pela idade e sem correção pelo balanço de nitrogênio é viável tanto sob o ponto de vista zootécnico quanto econômico.

\section{REFERÊNCIAS}

CARVALHO, F.B. Efeito da temperatura ambiente e da idade do frango de corte sobre o valor energético do milho, farelo e óleo de soja. 2010. 115f. Tese (Doutorado) - Universidade Estadual Paulista, Botucatu, SP.

FREITAS, B.C.F.; BAIÃO, N.C.; NUNES, I.J. et al. Digestibilidad de la grasa en las primeras semanas de vida del pollo de carne. In: CONGRESSO LATINO-AMERICANO DE AVICULTURA, 16., 1999, Lima. Anais... Lima: APAVI, 1999. p.356-359.

FREITAS, E.R.; SAKOMURA, N.K.; EZEQUIEL, J.M.B.; et al. Energia metabolizável de alimentos na formulação de ração para frangos de corte. Pesqui. Agropecu. Bras., v.41, p.107-115, 2006.
JUNQUEIRA, O.M.; ANDREOTTI, M.O.; ARAÚJO, L.F. et al. Valor energético de algumas fontes lipídicas determinado com frangos de corte. Rev. Bras. Zootec., v.34, p.2335-2339, 2005.

LARA, L.J.C.; BAIÃO, N.C.; ROCHA, J.S.R. et al. Influência da forma física da ração e da linhagem sobre o desempenho e rendimento de cortes de frangos de corte. Arq. Bras. Med. Vet. Zootec., v.60, p.970-978, 2008.

LEESON, S.; SUMMERS, J.D. Nutrition of the chicken. 4.ed. Guelph, Ontario, Canadá: University Books, 2001. 591p.

LOPEZ G.; LEESON, S. Assessment of the nitrogen correction factor in evaluating metabolizable energy of corn and soybean meal in diets for broilers. Poult. Sci., v.87, p.298-306, 2008.

MATTERSON, L.D.; POTTER, L.M.; STUTZ, M.W.; SINGSEN, E.P. The metabolizable energy of feed ingredients for chickens. Storrs: University of Connecticut, 1965. (Research report). $11 \mathrm{p}$.

MELLO, H.H.C.; GOMES, P.C.; ROSTAGNO, H.S. et al. Valores de energia metabolizável de alguns alimentos obtidos com aves de diferentes idades. Rev. Bras. Zootec., v.38, p.863-868, 2009.

NASCIMENTO, A.H.; GOMES, P.C.; ROSTAGNO, H.S. et al. Valores de energia metabolizável de farinhas de penas e de vísceras determinados com diferentes níveis de inclusão e duas idades das aves. Rev. Bras. Zootec., v.34, p.877-881, 2005.

NERY, L.R.; ALBINO, L.F.T.; ROSTAGNO, H.S. et al. Valores de energia metabolizável de alimentos determinados com frangos de corte. Rev. Bras. Zootec., v.36, p.1354-1358, 2007.

NUNES, V.N.; ROSTAGNO, H.S.; GOMES, P.C. et al. Coeficientes de metabolizabilidade da energia bruta de diferentes ingredientes para frangos de corte. Rev. Bras. Zootec., v.37, p.8994, 2008.

PAULA, A.; BRUM, P.A.R.; AVILA, V.S.; MAIER, J.C. Valores de energia metabolizável de farinha de carne e ossos e farinha de vísceras determinados com diferentes níveis de substituição para frangos de corte. Rev. Bras. Agrocienc., v.8, p.51-55, 2002. 
ROCHA, J.S.R.; LARA, L.J.C.; BAIÃO, N.C. et al. Efeito da classificação dos ovos sobre a uniformidade, o desempenho e o rendimento de abate de frangos de corte. Arq. Bras. Med. Vet. Zootec., v.60, p.1181-1187, 2008.

ROSTAGNO, H.S.; ALBINO, L.F.T.; DONZELE, J.L.; et al. Tabelas brasileiras para aves e suínos: composição de alimentos e exigências nutricionais. 3.ed. Viçosa: UFV/DZO, 2011. 252p.
SISTEMA de análises estatísticas e genéticas SAEGViçosa: UFV, 2007.

SOARES, K.R.; BERTECHINI, A.G.; FASSAN, E.J. et al. Valores de energia metabolizável de alimentos para pintos de corte na fase pré-inicial. Ciênc. Agrotec., v.29, p.238-244, 2005.

TUCCI, F.M.; LAURENTIZ, A.C.; SANTOS, E.A. et al. Determinação da composição química e dos valores energéticos de alguns alimentos para aves. Acta Sci. Anim. Sci., v.25, p.85-89, 2003. 